\title{
Anemia among Antenatal Mother in Urban Malaysia
}

\author{
Kim Lam Soh1*, Eusni Rahayu Mohd Tohit², Salimah Japar¹, Soh Kim Geok³, \\ Norhaslinda Binti Ab Rahman", Rosna Abdul Raman' \\ ${ }^{1}$ Nursing Unit, Department of Medicine, Faculty of Medicine and Health Science, Universiti Putra Malaysia, \\ Malaysia \\ ${ }^{2}$ Department of Pathology, Faculty of Medicines and Health Sciences, Universiti Putra Malaysia, Malaysia \\ ${ }^{3}$ Department of Sport Studies, Faculty of Education, Universiti Putra Malaysia, Malaysia \\ ${ }^{4}$ Hospital Ampang, Pandan Mewah, Ampang, Selangor, Malaysia \\ Email: sklam@upm.edu.my
}

Received December 2014

\section{Abstract}

An understanding of factors influencing haemoglobin $(\mathrm{Hb})$ level among antenatal mothers can help healthcare providers assess, take appropriate action and manage anaemia in this risk group more effectively. A cross-sectional study was conducted in urban areas in Malaysia to determine the $\mathrm{Hb}$ levels of antenatal mothers and their association with various socio-economic characteristics. Data for this study were collected from pregnant women during their first antenatal check-up at three selected polyclinics in Malaysia. Anaemia in pregnancy was determined by the Hb level recorded during the first and the last antenatal visits. Determination of $\mathrm{Hb}$ was either by a photo calorimetric method or by the Sahliís method. A structured self-administered questionnaire was used to identify the factors influencing $\mathrm{Hb}$ level among the antenatal mothers. This study found that 73 out of 217 mothers (33\%) were anaemic in that their $\mathrm{Hb}$ levels were below $11.00 \mathrm{~g} / \mathrm{dl}$. The findings also suggested that $\mathrm{Hb}$ levels among the antenatal mothers were influenced by various factors such as education level, occupation, and family income. Anaemia was generally more common among antenatal mothers who had a lower level of education and who were from a background of lower family income.

\section{Keywords}

Antenatal Mothers, Pregnant Women, Haemoglobin, Anemia, Maternal, Malaysia

\section{Introduction}

Anaemia in pregnancy, which is defined as a haemoglobin concentration $(\mathrm{Hb})<110 \mathrm{~g} / \mathrm{L}$, is one of the most common and widespread public health problems affecting more than 56 million women globally, two thirds of whom are in Asia. The global prevalence of anaemia in pregnancy is estimated to be approximately $41.8 \%$,

${ }^{*}$ Corresponding author.

How to cite this paper: Soh, K.L., Tohit, E.R.M., Japar, S., Geok, S.K., Ab Rahman, N.B. and Raman, R.A. (2015) Anemia among Antenatal Mother in Urban Malaysia. Journal of Biosciences and Medicines, 3, 6-11.

http://dx.doi.org/10.4236/jbm.2015.33002 
varying from a low of 5.7\% in the United States to a high of 75\% in Gambia [1]-[4]. According to World Health Organization [6], the highest prevalence of anaemia is in Africa and Southeast Asia. The report by WHO also highlighted India as the country with the highest prevalence of anaemia in pregnancy (49.7\%), against the global prevalence of $41.8 \%$. A multi-centre cross-sectional observational study conducted by Haniff et al. [2] found the overall prevalence of anaemia in pregnancy in Malaysia to be 35\%. They noted that the main factors which contributed to this disorder were young age, multiparity, and iron deficiency. In addition, Uche-Nwachi et al. [7] highlighted the association between $\mathrm{Hb}$ level and factors like parity and gravidity. Based on their findings, early commencement of antenatal care and close monitoring of the identified risk groups would reduce the incidence of anaemia during pregnancy. Medical problems during pregnancy such as anaemia, gestational diabetes mellitus, hypertension, heart problems and other illnesses, are widely recognized to cause many complications to maternal and foetal well-being. These complications may cause premature labour, still birth, abortion, and low birth weight. The association between anaemia with adverse maternal outcome such as puerperal sepsis, ante-partum haemorrhage, post-partum haemorrhage, and maternal mortality is well known. Anaemia contributes to an increase in the incidence of premature births, low birth weight babies, and prenatal mortality [8] [9]. Consequently, antenatal care is important to maintain women in good health during pregnancy, labour and child care. In Malaysia, antenatal care is provided to the antenatal mother starting from the early gestational period until delivery. This study investigates the variation in Hb levels among urban antenatal mothers in Malaysia, and how socio-economic demographics influence the prevalence of anaemia.

\section{Methods}

A cross-sectional study was carried out at three polyclinics located in the state of Selangor, Malaysia. The clinics received approximately 10 to 30 antenatal mothers for their first antenatal examination per month.

\subsection{Participants}

Selection criteria for this study were pregnant mothers who attended their first antenatal check-up at the polyclinics from November 2007 until January 2008. The exclusion criterion was antenatal mothers who came for subsequent follow-up visits.

\subsection{Instrument}

Demographic characteristics and $\mathrm{Hb}$ data were collected using a self-administered questionnaire adopted from the antenatal book record KIK/1 (a)/94. The questionnaire which was written in both English and Malay solicited information in two main areas: Section A: Socio-demographic characteristics and Section B: Pregnancy history. A pre-test questionnaire was conducted at the same polyclinics to check for clarity prior to the main data collection period. Anaemia in pregnancy was determined by either a photo calorimetric method or by the Sahliís method which was recorded during the first antenatal visits.

\subsection{Participants}

All eligible pregnant women who attended the antenatal check up at the three polyclinics were approached at the waiting area by the nurse in-charge and invited to participate in the study. Written consent was obtained from the participants before distribution of the questionnaires that were returned the same day after completion.

\subsection{Ethical Considerations}

The study was approved by the University's Medical Research Ethics Committee and the Malaysia National Institutes of Health Ethics Committee. Participation in this study was on voluntary basis; every respondent was given a copy of the consent form. An assurance of privacy and confidentiality of the information was also given to the participants.

\subsection{Data Analysis}

Data from completed survey questionnaires were entered into the Statistical Package for Social Sciences (SPSS) version 21 for descriptive and statistical analysis. Chi-square tests were used to determine the association between 
Hb level and participants' socio-economic characteristics. A significance level for the study was set at 0.05 .

\section{Results}

A tota 1 of 217 pregnant women participated in the study. The majority of the antenatal mothers were aged between 21 and 30, with a mean age of $27.92 \pm$ SD 4.77. The participants were predominantly Malay (72\%), with the remaining being Chinese (12\%), Indians (9\%), and other ethnic groups (7\%). Approximately $94 \%$ of the participants completed at least secondary school and $39 \%$ had tertiary education. Most of the participants $(\mathrm{n}=$ 137, 63\%) were working mothers. The results also showed that 180 (83\%) of the antenatal mothers were primid, and a majority (136, 63\%) had moderate family incomes between RM1500 to RM3500. Table 1 shows the main characteristics of respondents in terms of socio demographic variables.

$\mathrm{Hb}$ level of the antenatal mothers were recorded from their antenatal book records. Seventy-three (33\%) of the antenatal mothers had $\mathrm{Hb}$ levels of less than $11 \mathrm{gm} / \mathrm{dl}$, indicating anaemia. The relationships between the occurrence of anaemia and various socio-economic variables were examined. There was a significant association between $\mathrm{Hb}$ level and education level, $\chi^{2}(2)=13.10, \mathrm{p}=0.001$; Hb level and occupation, $\chi^{2}(1)=6.54, \mathrm{p}=0.01$; $\mathrm{Hb}$ level and income, $\chi^{2}(2)=9.91, \mathrm{p}=0.007$ (Table 2).

Table 1. Socio-demographic characteristics of antenatal mothers.

\begin{tabular}{|c|c|c|c|}
\hline Socio-demographic $(n=217)$ & $\mathbf{n}$ & $\%$ & Mean (SD) \\
\hline Age & & & $27.92(4.77)$ \\
\hline Less than 21 & 11 & 5 & \\
\hline 21 to 30 & 150 & 69 & \\
\hline More than 30 & 56 & 26 & \\
\hline \multicolumn{4}{|l|}{ Race } \\
\hline Malay & 156 & 72 & \\
\hline Chinese & 25 & 12 & \\
\hline Indian & 20 & 9 & \\
\hline Others (Aboriginal, Iban, Indonesia) & 16 & 7 & \\
\hline \multicolumn{4}{|l|}{ Educational level } \\
\hline Primary & 14 & 6 & \\
\hline Secondary & 119 & 55 & \\
\hline Tertiary & 84 & 39 & \\
\hline \multicolumn{4}{|l|}{ Occupation } \\
\hline Working & 137 & 63 & \\
\hline Not working & 80 & 37 & \\
\hline \multicolumn{4}{|l|}{ Parity } \\
\hline Primidgavida & 180 & 83 & \\
\hline Multipara & 37 & 17 & \\
\hline \multicolumn{4}{|l|}{ Family income } \\
\hline Less than RM1500 & 36 & 16 & \\
\hline RM1500 - RM3500 & 136 & 63 & \\
\hline More than RM3500 & 45 & 21 & \\
\hline
\end{tabular}


Table 2. Association between haemoglobin level and socio-demographic profile.

\begin{tabular}{|c|c|c|c|c|c|}
\hline \multirow{3}{*}{ Socio-demographic $(n=217)$} & \multicolumn{2}{|c|}{ Hb level } & \multirow[b]{3}{*}{ df } & \multirow[b]{3}{*}{$\chi^{2}$} & \multirow[b]{3}{*}{ p-value ${ }^{*}$} \\
\hline & $<11$ gm/dl & $\geq 11 \mathrm{gm} / \mathrm{dl}$ & & & \\
\hline & $(\mathrm{n}=73,34 \%) \mathrm{n}(\%)$ & $(n=144,66 \%) n(\%)$ & & & \\
\hline \multicolumn{6}{|l|}{ Age } \\
\hline Less than 21 & $7(64)$ & $4(36)$ & & & \\
\hline 21 to 30 & $48(32)$ & $102(68)$ & 2 & 4.67 & 0.10 \\
\hline More than 30 & $18(32)$ & $38(68)$ & & & \\
\hline \multicolumn{6}{|l|}{ Race } \\
\hline Malay & 46 (29.5) & $110(70.5)$ & & & \\
\hline Chinese & $9(36)$ & $16(64)$ & 3 & 7.60 & 0.06 \\
\hline Indian & $12(60)$ & $8(40)$ & & & \\
\hline Others (Aboriginal, Iban, Indonesia) & $6(37.5)$ & $10(62.5)$ & & & \\
\hline \multicolumn{6}{|l|}{ Educational level } \\
\hline Primary & $6(43)$ & $8(57)$ & & & \\
\hline Secondary & $51(43)$ & $68(57)$ & 2 & 13.10 & $0.001^{*}$ \\
\hline Tertiary & $16(19)$ & $68(81)$ & & & \\
\hline \multicolumn{6}{|l|}{ Occupational } \\
\hline Working & $37(27)$ & $100(73)$ & & & \\
\hline Not working & $36(45)$ & $44(55)$ & 1 & 6.54 & $0.01^{*}$ \\
\hline \multicolumn{6}{|l|}{ Parity } \\
\hline Primigavida & $57(32)$ & $123(68)$ & & & \\
\hline Multipara & $16(43)$ & $21(57)$ & 1 & 1.36 & 0.24 \\
\hline \multicolumn{6}{|l|}{ Family income } \\
\hline Less than RM1500 & $20(56)$ & $16(44)$ & & & \\
\hline RM1500 - RM3500 & $42(31)$ & 94 (69) & 2 & 9.91 & $0.007^{*}$ \\
\hline More than RM 3500 & $11(24)$ & $34(76)$ & & & \\
\hline
\end{tabular}

" p value determined by Chi-square analysis.

\section{Discussion}

The study sought to determine the Hb level in antenatal mothers and their association with various socio-demographic characteristics in urban areas in Malaysia. Pregnant women having haemoglobin level of less than 11 $\mathrm{gm} / \mathrm{dl}$, indicating anaemia, face a serious health risk. It is a common cause of morbidity in pregnancy worldwide [10]. Lifestyle, work or household income in urban areas may also affect the Hb level among the antenatal mothers [11], as indicated in the present study.

The majority of the antenatal mothers in this study area had Hb levels of more than $11 \mathrm{gm} / \mathrm{dl}$ ( $\mathrm{n}=217 ; 66 \%$ ). Approximately, 63\% $(n=73)$ of anaemic antenatal mothers at these three antenatal polyclinics were Malays. This finding was expected as Malay mothers constitute the majority of antenatal mothers who come for their antenatal check-up at the three antenatal polyclinics. In other words, these statistics reflects the proportion of different ethnic groups in Malaysian context. A previous larger study conducted by Haniff et al. [2] found that 35\% (n = 1072) antenatal mothers from 56 clinics had Hb levels of less than $11 \mathrm{gm} / \mathrm{dl}$. This result was very close to that $(\mathrm{n}=$ 217, 34\%) found in the present study. Haniff et al. also found the prevalence of anaemia to be higher among the Malays and Indians [2] but, as stated earlier, ethnicity was not a significant factor in the present study.

Approximately 150 (69\%) of the antenatal mothers in this study were in an age range of 21 to 30 years. A similar finding was also reported in a study by Sahoo [12] who found that pregnant mothers between 21 - 30 years of age accounted for the majority (78\%) of their study population. However, Haniff et al. [2] reported a lower percentage of this age group (54\%) among the pregnant women sampled. This present study found no significant association between $\mathrm{Hb}$ level and age among pregnant mothers. Contrary, the observation by Haniff et al. [2] found a significant association between age and low $\mathrm{Hb}$ level among pregnant mothers in Malaysia. Sahoo also noted that age was significantly associated with Hb level [12]. This age group (21 to 30 years) is considered the productive age group; therefore it may have contributed to a higher number of successful pregnancies [13]. 
Most of the participants in the present study (55\%) have secondary school education similar to previous study $54 \%$ [2]. This study found that education level was significantly associated with the Hb level of the antenatal mothers. The majority of mothers with higher education could be more concerned about their health and the health of their foetus. This observation is supported by the findings of a study conducted in the United States where it was shown that the chances of anaemia during pregnancy declined with the education level of the mother [14]. In the context of the current study, only $19 \%$ of antenatal mothers with tertiary education were anaemic, whereas anaemia was detected in $43 \%$ of the rest of the study group. This shows that antenatal mothers with higher education level might have more awareness about the dangers of anaemia to their pregnancy, and they therefore made conscious effort to maintain their $\mathrm{Hb}$ levels at acceptable levels.

The majority of the antenatal mothers $(\mathrm{n}=137,63 \%)$ in this study were working. Among working mothers, $27 \%$ had $\mathrm{Hb}$ levels less than $11 \mathrm{gm} / \mathrm{dl}$, and were therefore anaemic, as compared with almost half $45 \%$ of the non-working antenatal mothers who were similarly afflicted. This finding consequently suggested a significant association between $\mathrm{Hb}$ level and antenatal mother's occupational level. According to Meda et al. [15] antenatal mothers' occupation is significantly associated with anemia in pregnancy. The number of working antenatal mothers who had higher $\mathrm{Hb}$ levels in this study could be due their contribution to an increased household income that allowed for better nutrition. Consistent with this reasoning, the present study also found a significant association between low $\mathrm{Hb}$ level and family income. Low family income increased the chances of anaemia in pregnant women. The results of this study matched those reported by Frith-Terhune et al. [16] that showed family income being positively associated with Hb level.

\section{Conclusion}

Anaemia during pregnancy is hazardous to both mother and foetus. This is a health issue that requires urgent attention in Malaysia as the prevalence of low Hb level is alarming among certain groups. Various socio-economical characteristics of pregnant women such as age, education level, occupation and family income are associated with low Hb levels. The findings of this study could provide insights for health care providers to take into account these variables in maintaining $\mathrm{Hb}$ at safe levels during pregnancy. The current study examined antenatal mothers at three urban antenatal polyclinics. Future study is recommended to address the issue of anaemia among pregnant mothers in rural areas so as to have a more comprehensive view of the problem.

\section{Acknowledgements}

The authors would like to express special thanks to the Director General of Health Malaysia for permission to publish this paper, and to hospital directors for their cooperation in this study.

\section{References}

[1] Benoist, B.D., McLean, E., Egll, I. and Cogswell, M. (2008) Worldwide Prevalence of Anaemia 1993-2005: WHO Global Database on Anaemia. World Health Organization, Geneva.

[2] Haniff, J., et al. (2007) Anemia in Pregnancy in Malaysia: A Cross-Sectional Survey. Asia Pacific Journal of Clinical Nutrition, 16, 527-536.

[3] Yajnik, C.S., et al. (2003) Neonatal Anthropometry: The Thin-Fat Indian Baby. The Pune Maternal Nutrition Study. International Journal of Obesity, 27, 173-180. http://dx.doi.org/10.1038/sj.ijo.802219

[4] Goonewardene, M., Shehata, M. and Hamad, A. (2012) Anaemia in Pregnancy. Best Practice \& Research Clinical Obstetrics \& Gynaecology, 26, 3-24. http://dx.doi.org/10.1016/j.bpobgyn.2011.10.010

[5] Pena-Rosas, J.P. and Viteri, F. (2009) Effects and Safety of Preventive Oral Iron or Iron + Folic Acid Supplementation for Women during Pregnancy. Cochrane Database Systematic Review, 4, Article ID: CD004736. http://dx.doi.org/10.1002/14651858.CD004736.pub3

[6] World Health Organization (2008) The Prevalence of Anaemia in Women: A Tabulation of Available Information. WHO, Geneva.

[7] Uche-Nwachi, E., et al. (2010) Anaemia in Pregnancy: Associations with Parity, Abortions and Child Spacing in Primary Healthcare Clinic Attendees in Trinidad and Tobago. African Health Sciences, 10, 66-70.

[8] Rijken, M.J., et al. (2014) Quantifying Low Birth Weight, Preterm Birth and Small for Gestational Age Effects of Malaria in Pregnancy: A Population Cohort Study. PLoS One, 9, 1-8. http://dx.doi.org/10.1371/journal.pone.0100247

[9] Woods, C.R., Davis, D.W., Duncan, S.D. and Myers, J.A. (2014) Variation in Classification of Live Birth with New- 
born Period Death versus Fetal Death at the Local Level May Impact Reported Infant Mortality Rate. BMC Pediatrics, 14, 108-117. http://dx.doi.org/10.1186/1471-2431-14-108

[10] Whitfield, C.R. (1995) Blood Disorders in Pregnancy. In: Whitfield, C.R., E., Dewhurst's Textbook of Obstetrics \& Gynaecology for Postgraduates, Blackwell Science Ltd., Oxford, 228-253.

[11] Ramachandran, P. (2002) Maternal Nutrition: Effect on Fetal Growth and Outcome of Pregnancy. Nutrition Reviews, 60, S26-S34. http://dx.doi.org/10.1301/00296640260130704

[12] Sahoo, S. and Panda, B. (2006) A Study of Nutritional Status of Pregnant Women of Some Villages in Balasore District, Orissa. Journal of Human Ecology, 20, 227-232.

[13] Eijkemans, M.J.C., et al. (2014) Too Old to Have Children? Lessons from Natural Fertility Populations. Human Reproduction.

[14] Adebisi, O.Y. and Strayhorn, G. (2005) Anemia in Pregnancy and Race in the United States: Blacks at Risk. Family Medicine, 37, 655-662.

[15] Meda, N., Mandelbrot, L., Cartoux, M., Dao, B. and Ouangre, Â.A. (1999) Anaemia during Pregnancy in Burkina Faso, West Africa, 1995-96: Prevalence and Associated Factors. Children, 5, 916-922.

[16] Frith-Terhune, A.L., Cogswell, M.E., Khan, L.K., Will, J.C. and Ramakrishnan, U. (2000) Iron Deficiency Anemia: Higher Prevalence in Mexican American than in Non-Hispanic White Females in the Third National Health and Nutrition Examination Survey 1988-1994. The American Journal of Clinical Nutrition, 72, 963-968. 